\title{
GEREJA DENGAN PARADIGMA PEMBARUAN DITINJAU DARI PERSPEKTIF TEOLOGI AGAMA DAN MASYARAKAT
}

\author{
Pdt. Yunny Jones Akal, Th.D.1
}

\begin{abstract}
Abstrak
Gereja atau umat Allah diharapkan selalu berada dalam perubahan positif, agar tegar dan siap terus melaksanakan tanggung jawab vertical dan horizontal. Prinsip yang perlu adalah gereja memberi Kontribusi bagi masyarakat. Peluang-peluang seperti halnya mengembangkan pelayanan berdasarkan panggilan Allah, bermotif kasih, dan berorientasikan perbuatan baikmenjadi keßuatan lahirnya pengakuan "Allahmu adalah Allahku, Kristusmu adalah Kristusku"
\end{abstract}

\section{PENDAHULUAN}

Perubahan terjadi dalam matra kodarti. Keberadaan kodrati berubah menurut pengaturan Penciptanya. TUHAN Allah, Oknum Yang tidak berubah, Pencipta langit dan bumi serta segala isinya, mempunyai kehendak bagi umat atau gereja-Nya dalam perubahan global.

Pandangan teologi agamawi dan masyarakat berubah menurut konteksnya. Perubahan pandangan ini sedang dialami oleh umat Allah di Indonesia sekarang. Perubahan tersebut sebenarnya menjadi tantangan dan peluang pelayanan bagi kita. Namun, apakah gereja Tuhan selalu berada dalam perubahan positif, sehingga tegar menghadapi tantangan dan siap mengisi peluang pelayanan masa kini?

Kita menetapkan tujuan agar semua umat Allah selalu berada dalam perubahan positif, agar tegar dan siap terus melaksanakan tanggung jawab berdasarkan panggilanNya. Tujuan ini didasarkan pada Surat Roma 12:1,2, dan dihubungkan dengan tantangan dan harapan dalam perspektif Teologi Agama dan Masyarakat Indonesia masa kini.

Bahasan makalah ini disusun dalam tiga bagian utama, yaitu Pengertian Istilahistilah Dasar yang digunakan, Tantangan dan Harapan dalam Perspektif Teologi Agama dan Masyarakat Indonesia, dan Peluang Pelayanan bagi Gereja Tuhan di Indonesia. Istilah "globalisasi" tidak dibahas secara rinci. Menurut arti sederhana, globalisasi digunakan untuk perkembangan global (globe/dunia/menyeluruh), sehingga batasbatas yang dulunya "ketat" menjadi "fleksibel" dan hubungan-hubungan antar manusia, masyarakat, negara dan agama menjadi lebih "bebas".

1 Th.D. dari Asian Center for Theological Studies and Mission (ACTS), Program Pascasarjana Universitas Serikat Asia (Asia United Theological Universiry), Seoul, Korea Selatan dengan Disertasi, "The Question of Application of Theological Exclusivism in the Missionary Context in Indonesia." Ia adalah dosen Studi Agama IFTK Jaffray Jakarta dan Rektor institusi ini tahun 2001-2006. 


\section{PENGERTIAN ISTILAH-ISTILAH DASAR YANG DIGUNAKAN}

\section{A. Umat Allah atau Gereja Tuhan}

\section{Umat Allah}

Kata-kata "Umat Allah" digunakan untuk orang-orang yang diselamatkan oleh TUHAN Allah dalam sejarah umat manusia, termasuk dalam Perjanjian Lama dan Baru. Ayat-ayat Alkitab yang berkaitan dengan istilah ini adalah antara lain: I Petrus 2:9,10.

2. Gereja Tuhan

Istilah "Gereja Tuhan" digunakan secara hakikat untuk orang-orang pilihan Allah (Kej. 3:9,15,21; Ef. 1:4). Mereka adalah jemaat (milik) Kristus dan disebut sebagai orang-orang yang bahagia (Mat. 16:18; Wah. 22:14).

\section{B. Paradigma Pembaruan}

1. Pengertian Leksikal

Paradigma adalah "kerangka berpikir". ${ }^{2}$ Kata ini terbentuk dari "Para" (near, beside, above, among), ditambah "deigma" (example). Kata kerjanya (paradeigmatizo), dapat diterjemahkan: I show alongside atau I am public example. ${ }^{3}$ Dengan demikian, paradigma dapat diartikan sebagai cara berpikir baru, yang muncul di samping, di atas, atau dari tengah model berpikir lama.

Paradigma pembaruan berarti bahwa kerangka berpikir dibarui atau dibarukan untuk pembaruan lanjutan. Cara berpikir ini diharapkan dapat membawa kemajuan dalam ibadah kepada Allah, dan pelayanan komprehensif kepada sesama.

2. Pengertian Alkitabiah

Kata paradeigmatizo dipakai dalam Matius 1:19 (paradeigmatisai - to expose to a publik disgrace), dan Ibrani 6:6 (paradeigmatizontas - putting to open shame). ${ }^{4}$ Paradigma dalam kedua ayat ini negatif.

Dua teks yang dipakai sebagai dasar studi selanjutnya, yaitu Matius 1:19-24 dan Roma 12:2. Pertama, menurut teks Matius 1:19-24, Yusuf memiliki paradigma negatif (ayat 19), Yusuf menerima kebenaran dari Allah melalui malaikat-Nya (ayat 20-23), dan paradigma negatif Yusuf berubah menjadi positif, sesuai dengan kehendak Allah (ayat 24). Kedua, menurut teks Roma 12:2, ada larangan (Do not conform any longer to the pattern of this world $c o+$ form), , perintah (but the transformed by the renewing of your mind), dan

2 Anton M. Moeliono dkk., eds., Kamus Besar Bahasa Indonesia, Cetakan ke-2, Jakarta: Balai Pustaka, hal. 648.

${ }^{3}$ Lihat Strong, No. 3844, 1165, 3856.

${ }^{4}$ Francis Brown, dkk., The New Brown-Driver-Briggs-Gesenius Hebrew ang English Lexicon, Peabody, Massachustts: Hendrikscon Publishers, 1979, hal. 737; Joseph H. Thayer, Thayer's GreekEnglish Lexicon of the New Testament, Cet. Ke-20, Grand Rapids, Michigan: Baker Book House, 1992, hal. 480 . 
sasaran (Then you will be able to test and approve what God's will is his good, pleasing, and perfect will). 5

Berdasarkan uraian ini, nyata bahwa ada: (1) Sifat paradigma (negatifpositif), (2) Standar paradigma (duniawi-surgawi), (3) Intervensi paradigma (dari unsur luar), (4) Transformasi paradigma (terjadi dalam nouns yang mencakup pikiran, perasaan dan kehendak), dan (5) Pembaruan paradigma (untuk mengetahui kehendak Allah).

3. Pengertian Praktis

Paradigma pembaruan yang diharapkan adalah yang bermakna teologis dan etis. Artinya, setiap pembaruan didasarkan pada kebenaran Allah dan ditata untuk meningkatkan kebaikan diri sendiri dan sesama.

\section{Perspektif Teologi Agama dan Masyarakat}

1. Pengertian Teologi Agama

a. Teologi

Teologi adalah ilmu pemgetahuan Allah (tentang Allah) dalam hubungan dengan semua ciptaan-Nya. Jikalau dihubungkan dengan agama, Teologi Agama memberikan makna antara lain agama dalam perspektif teologis.

b. Agama

Agama, secara etimologis, terbentuk dari "A-gam-a" (A = tidak; gam = pergi; a = sifatnya), sehingga "Agama" berarti abadi (eternal); Agama adalah suatu yang abadi (eternally). ${ }^{6}$ Menurut tulisan Julien Ries, kata agama (religion) berhubungan dengan kata "relegere 'to assemble", sehingga artinya menjadi "the essembling and transmiting of the ancestral worship of the gods." Kemudian, kata "religio, yang diambil dari religare, 'to bind together'" oleh orang Kristen abad ketiga masehi, menjadi "a set of doctrines and practices that forms man's relationship with the divinity."7 Secara sistem, agama adalah sistem kepercayaan, sikap, dan praktek agamawi yang dilakukan oleh manusia kepada Allah (Ertel: 769). Sistem ini dapat dilihat dari perspektif Samawi dan Wadi'i, sehingga ada istilah agama Samawi dan Wadi'i.

Teologi Agama adalah ilmu pengetahuan Allah dalam hubungan-Nya dengan sistem kepercayaan, sikap dan perbuatan manusia. Dengan kata lain, Teologi Agama adalah agama dalam perspektif teologis. Pertanyaan penting adalah: "Apa fungsi agama bagi masyarakat?"

2. Pengertian Masyarakat

Masyarakat secara sederhana berarti kelompok orang yang berada dalam lingkup tertentu. Lingkup ini dikenal dengan istilah antara lain, kebudayaan (Masyarakat Batak, dll), tempat (Masyarakat Kota, dst.), dan sistem sosio-religius (Masyarakat Madani, dls.). Dengan demikian, kelompok-kelompok muncul secara natural sesuai konteks masing-masing sehingga paling kurang ada "ingroup" yang dapat menyebabkan (membawa) ketegangan atau ketentraman, tantangan atau harapan.

\footnotetext{
${ }^{5}$ Kenneth Barker, ed., The NIV Study Bible, Grand Rapids, Michigan: Zondervan Bible Pulishers, 1985, hal. 2188.

${ }^{6}$ Lihat kata Agama dalam Ensiklopedi Indonesia.

${ }^{7}$ Julien Ries, The Origins of Religions, Grand Rapids, Michigan: William B. Eerdmans Publishing Company, 1994, hal. 7.
} 


\section{TANTANGAN DAN HARAPAN DALAM PERSPEKTIF TEOLOGI AGAMA DAN MASYARAKAT INDONESIA}

\section{A. Tantangan dan Harapan dalam Perspektif Teologi Agama}

1. Kebangkitan Agama-agama

Orang-orang yang beragama "bangkit" sejalan dengan ajaran agamawi dan pengarah globalisasi. Contoh-contoh ajaran ini adalah "Kharma Phala", "Sunyata", "Ihsan", dan "Kasih". Aktualisasinya terwujud dalam perkataan dan perbuatan inter dan antar umat beragama di Indonesia. Tentu buah kehidupan agamawi menentukan tingkat penghayatan setiap individu orang yang beragama tersebut.

Kebangkitan agama-agama membawa paling kurang dua akibat logis, yaitu "kedewasaan" dan "kesaksian" umat beragama. Pertama, banyak (kalau tidak semua) orang yang beragama mengharapkan bahwa orang-orang yang beragama benar-benar menjadi "orang baik". Misalnya, orang menjadi "rahmat" bagi semesta alam dan orang menjadi "berkat" bagi sesama. Kedua, aktualisasi identitas terjadi melalui nyanyian, sandiwara, khotbah, pengajaran, gaya hidup, dls. Seharusnya, "kesaksian" agamawi dibuat tanpa paksaan sehingga istilah "Kristenisasi" dan "islamisasi" tidak menjadi "ancaman identitas agama".

2. Hubungan Agama-agama

Manusia sudah hidup dalam sosial yang baik dan jahat sejak penciptaannya (Kej. 1:3; 2:9; 3:15; 4:1-16). Manusia yang beragama dapat berbuat baik (seperti menghindari percabulan), dan berbuat jahat (seperti membunuh orang lain atau ibu kandungnya). Harapan agamawi adalah antara lain: (1) Jangan membunuh, jangan berzinah, jangan mencuri (Kel. 20:13-15), (2) "Amar Ma'ruf dan Nahi Munkar" (Q. Ali Imran [3]:104), dan (3) "Kasihilah seorang akan yang lain" (Yoh. 15:17b).

Orang-orang yang beragama dapat hidup rukun dalam perspektif ciptaan Allah. Namun, jikalau "in-group" dan "out-group" agamawi berbenturan, kiranya setiap umat agamawi membawa diri dengan tanggung jawab penuh tentang kebenaran "ekslusif" dan "sosial". Ada "kepercayaan (aqidah)" dan ada "kehidupan bermasyarakat (...mu'amalah)".8 Ada "kebenaran hakiki" (Yesus Kristus adalah satu-satunya Jalan, Kebenaran, dan Kehidupan) dan ada "kebenaran sosial" (cara ibadah gerejawi).

${ }^{8}$ Abd. Majid, Tantangan dan Harapan Umat Islam di Era Globalisasi, Bandung: CV. Pustaka Setia, 2000, hal. 32 . 


\section{B. Tantangan dan Harapan dalam Perspektif Masyarakat Indonesia}

1. Masyarakat Madani

Konsep "Masyarakat Madani" (Civil Society) atau "Masyarakat Madinah" sudah dikenal oleh banyak orang di Indonesia, terutama yang beada di kota-kota besar seperti Jakarta dan Surabaya. Penilaian masyarakat berbeda menurut cara pandang masing-masing, sehingga istilah ini menjadi tantangan atau harapan.

Jikalau suatu masyarakat tertentu menguasai daerah tertentu berdasarkan aqidah agamawi, maka kelompok lain akan terancam dan dapat menimbulkan konflik horizontal terus-menerus. Sebaliknya, kesadaran religius - yang menghasilkan manusia beradab - membawa kontribusi maksimal bagi semua manusia dalam kelompok agama apa pun. Inilah Harapan dalam istilah "rahmatan li al'alamin" dan "pembawa shalom."

2. Masyarakat Pembaruan

Individu atau kelompok masyarakat Indonesia sedang dilanda oleh sistem globalisasi. Pengaruh negatif dan positifnya terasa sekali. Hubungan "dalam luar" yang semakin luas dan perkembangan ilmu pengetahuan, teknologi, dan ekonomi menurut sikap kristis dan kerja inovatif masyarakat kita.

Masyarakat berharap bahwa gereja membawa kemajuan, komprehensif yaitu pembaruan spiritual, sosial, dan psikologis. Sebab itu, para pemimpin umat Allah meningkatkan peran agama sesuai dengan teori solidaritas dan makna sosialnya sesuai dengan fungsi: edukatif, transformatif, persaudaran, dan pengawasannya (Djamari: 92-106 dan Hendropuspito: 38-57). Beberapa contoh: (1) Pemimpin masyarakat tidak melakukan KKN, tetapi menyatakan persepsi untuk kepentingan bersama; (2) Gereja menunjukkan kasih dalam perbuatan; (3) Pemimpin gereja mengajarkan kebenaran konprehensif secara objektif; (4) Gereja hidup dalam transformasi yang bersinambung; (5) Gereja mengaktualisasikan persaudaran berdasarkan prinsip humaniora dan kasih Kristus; (6) Pemimpin gereja turut mengawasi pemerintah sesuai dengan fuingsi kenabiannya.

Masih ada harapan bagi gereja Tuhan di Indonesia. Orang-orang yang beragama, "semakin rasional dan dekat" dengan umat pilihan TUHAN Allah. Tantangan bukan alat picu konflik batin dan soaial, melainkan alat pacu pembaruan spiritual, soaial dan psikologis. TUHAN Allah dapat mentransformasikan hidup orang-orang berdosa sekalipun mereka berada dalam benteng yang berlapis-lapis.

Paradigma yang terbuka kepada Allah adalah sarana kongnitif untuk menikmati campurtangan Pencipta kita dalam segala bidang kehidupan. Ingatlah bahwa tidak ada yang mustahil bagi TUHAN kita. 


\section{PELUANG PELAYANAN BAGI GEREJA TUHAN DI INDONESIA}

Uraian bab ini didasarkan pada Surat Roma 12:13. Dua prinsip dasar pelayanan gereja adalah Ibadah Sejati dan Pembaruan Budi (Rm. 12:1-2). Tiga pokok bahasan dikaitkan dengan peluang pelayanan gereja Tuhan di Indonesia masa kini, yaitu panggilan Allah, kasih Kristus, dan perbuatan baik.

\section{A. Pelayanan Berdasarkan Panggilan Allah (Rm. 12:3-8)}

1. Pengertian Pelayanan Berdasdarkan Kasih Karuia

Setiap orang merasa, berpikir, dan berbuat sesuatu sesuai dengan karunia Allah, sekaligus menguasai diri sesuai dengan kadar imannya dan konteks masyarakat. Ia adalah individu dalam komunitas dinamis. Ia memiliki karunia untuk kepentingan bersama.

2. Contoh-contoh Pelayanan Berdasarkan Kasih Karunia

Pemikir berpikir objektif-kontekstual. Pelaksana berpikir dan bertindak korelasional. Jikalau dua contoh ini dibuat sinergis, maka pemimpin didukung oleh pengikutnya dengan usaha kreatif dan inovatif. Sebaliknya, pemimpin "kesepian" dan masyarakatnya "kebingungan".

\section{B. Pelayanan Bermotifkan Kasih Kristus (Rm. 12:9-21; 13:8-14)}

1. Konsepnya adalah Mengasihi Sesama sebagai Kegenapan Hukum Taurat

Tertulis: "Hendaklah kasih itu jangan pura-pura! Jauhilah yang jahat dan lakukanlah yang baik" (Rm. 2:9); "Janganlah berhutang apa-apa kepada siapa pun juga, tetapi hendaklah kamu saling mengasihi. Sebab barangsiapa mengasihi sesamanya, ia sudah memenuhi Hukum Taurat" (Rm. 13:8); “...Kasihilah sesamamu manusia seperti dirimu sendiri!" (Rm. 13:9).

2. Penerapan Kasih kepada Sesama

Orang yang menerapkan kasih Kristus kepada sesama, ditandai oleh beberapa sikap dan perbuatan berikut. Pertama, ia menghormati orang lain lebih dulu (Rm. 12:10). Kedua, ia membantu orang lain dengan apa yang ada padanya (Rm. 12:13). Ketiga, ia tidak membalas kejahatan dengan kejahatan, tetapi mengusahakan perdamaian (Rm. 12:17-21). Keempat, ia tidak berbuat jahat, tetapi hidup dengan sopan (Rm. 13:9-13). Kelima, ia tidak merawat tubuhnya untuk memuaskan keinginannya, tetapi melakukan ibadah yang sejati untuk memuaskan hati Yesus Kristus (Rm. 13:14). 


\section{Pelayanan Berorientasikan Perbuatan Baik (Rm. 13:1-7)}

1. Konsepnya adalah Berbuat Baik

Warga Negara yang baik tidak berbuat jahat, tetapi berbuat baik (Rm. 13:16). Jikalau berbuat jahat, ia malu mengaku dan berubah. Jikalau berbuat baik, ia bangga dan berdedikasi lebih lagi.

2. Penerapan Perbuatan Baik

Umat Allah memberikan kontribusi bagi pembangunan bangsa. Kita memberikan apa yang menjadi kewajiban bersama, seperti pajak. Kita menghormati "orang yang berhak menerima hormat" (Rm. 13:7).

\section{PENUTUP}

\section{A. Kesimpulan}

Gereja atau umat Allah diharapkan selalu berada dalam perubahan positif, agar tegar dan siap terus melaksanakan tanggung jawab vertikal dan horizontalnya. Apakah orang yang beragama selalu memberikan kontribusi positif bagi masyarakat luas?

Sekalipun ada tantangan seperti konfik internal dan eksternal karena kebangkitan agama-agama dan kesadaran masyarakat agamawi, namun masih ada harapan bagi umat Allah di Indonesia. Dua prinsip yang perlu diingat dan diterapkan.

1. Gereja dapat bekerjasama dengan orang yang beragama lain dalam bidang sosial kemasyarakatan. Biarkan istilah "Agamaku adalah agamaku, agamamu adalah agamamu" berada dalam kehidupan masyarakat kita sampai ada pengakuan transformatif, "Allahmu adalah Allahku, Kristusmu adalah Kristusku."

2. Transformasi hidup datang dari TUHAN Allah, yang telah menyatakan diri-Nya dalam Yesus Kristus. Usaha paksa agamawi tidak cocok dengan kebenaran Alkitabiah dan keyakinan manusia. Inatlah perkataan Yesus Kristus, Perantara Yang Mahatahu, Juruslamat manusia, sesuai dengan tulisan rasul Yohanes: "Tidak ada seorang pun yang dapat datang kepada-Ku, jikalau ia tidak ditarik oleh Bapa yang mengutus Aku, dan ia akan Kubangkitkan pada akhir zaman" (Yoh. 8:44).

\section{B. Saran-saran}

1. Jadilah orang yang beribadah dalam "Ibadah yang sejati" dan berubah oleh pembaruan Ilahi untuk mengetahui kehendak Allah, sehingga pikiran dan tindakan kita menyenangkan hati-Nya.

2. Jadilah komunikator Injil melalui pelayanan professional-kontekstual. Injil harus diberitakan dalam konteks khusus, sebab itulah tanggung jawab spiritual-sosial kita, dengan keyakinan bahwa iman timbul dari pendengaran tentang firman Kristus. 


\section{Endnotes:}

${ }^{1}$ Tulisan ini pernah disampaikan dalam orasi ilmiah wisuda Sarjana dan Pascasarjanake-30 dan Dies Natalis ke-71 STT Jaffray, September 2004. Th.D. dari Asian Center for Theological Studies and Mission (ACTS), Program Pascasarjana Universitas Serikat Asia (Asia United Theological Universiry), Seoul, Korea Selatan dengan Disertasi, "The Question of Application of Theological Exclusivism in the Missionary Context in Indonesia.” Ia adalah dosen Studi Agama IFTK Jaffray Jakarta dan Rektor institusi ini tahun 2001-2006.

${ }^{2}$ Anton M. Moeliono dkk., eds., Kamus Besar Bahasa Indonesia, Cetakan ke-2, Jakarta: Balai Pustaka, hal. 648.

${ }^{3}$ Lihat Strong, No. 3844, 1165, 3856.

${ }^{4}$ Francis Brown, dkk., The New Brown-Driver-Briggs-Gesenius Hebrew ang English Lexicon, Peabody, Massachustts: Hendrikscon Publishers, 1979, hal. 737; Joseph H. Thayer, Thayer's GreekEnglish Lexicon of the New Testament, Cet. Ke-20, Grand Rapids, Michigan: Baker Book House, 1992, hal. 480 .

${ }^{5}$ Kenneth Barker, ed., The NIV Study Bible, Grand Rapids, Michigan: Zondervan Bible Pulishers, 1985, hal. 2188.

${ }^{6}$ Lihat kata Agama dalam Ensiklopedi Indonesia.

${ }^{7}$ Julien Ries, The Origins of Religions, Grand Rapids, Michigan: William B. Eerdmans Publishing Company, 1994, hal. 7.

${ }^{8}$ Abd. Majid, Tantangan dan Harapan Umat Islam di Era Globalisasi, Bandung: CV. Pustaka Setia, 2000, hal. 32.

\section{KEPUSTAKAAN}

Al-Bantani, Syekh Muhammad An-Nawawi, Mencari Cahaya Ilahi Menuju Keimanan Sejati Mencapai Keselamatan Dunia Akhirat, Terjemahan K.H. Abdullah Zakiy Al-Kaaf, Bandung: CV. Pustaka Setia, 2001.

Barker, Kenneth, ed., The NIV Study Bible, Grand Rapids, Michigan: Zondervan Bible Publishers, 1985.

Brown, Fancis, dkk., The New Brown-Driver-Briggs-Gesenius Hebrew and English Lexicon, Peabody, Massachusetts: Hendrickson Publishers, 1979.

Djamari, Agama dalam Perspektif Sosiologi, Bandung: CV. Alfabeta, 1993.

Hendropuspito, D., Sosiologi, Jakarta: PT BPK Gunung Mulia/Kanisius, 1983.

Hidayat, Komaruddin dan Muhammad Wahyuni Nafis, Agama Masa Depan Perspektif Filsafat Perennial, Jakarta: Paramadina, 1995.

Majid, Abd., Tantangan dan Harapan Umat Islam di Era Globalisasi, Bandung: CV Pustaka Setia, 2000. 
Moeliono, Anton M. dkk., Kamus Besar Bahasa Indonesia, Cet. Ke-2. Jakarta: Balai Pustaka, 1989.

Ries, Julien, The Origins of Religions, Grand Rapids, Michigan: William B. Eerdmans Publishing Comapany, 1994.

Thayer, Joseph H., Thayer's Greek-English Lexicon of the New Testament, Cet. Ke-20. Grand Rapids, Michigan: Baker Book Hous, 1992.

Urbaningrum, Anas., Menuju Masyarakat Madani Pilar dan Agenda Reformasi, Cet. Ke-2. Jakarta: Yarsif Watampone, 1999.

Strong, James, The Exhaustive Concordance of the Bible, McLean, Virginia: MacDonald Publishing Company, n.d. 